Volume 1 Issue 1

June 2016

\title{
Decision-making processes when paramedics refer low acuity patients away from hospital: a scoping review.
}

Kelly Sheffield MHlthSc(c)

La Trobe University, Victoria, Australia.

Ambulance Victoria, Victoria, Australia.

Peter O’Meara PhD

La Trobe University, Victoria, Australia.

Glenda Verrinder PhD MHlthSc

La Trobe University, Victoria, Australia.

\section{Recommended Citation}

Sheffield K, O’Meara P and Verrinder G. Decision-making processes when paramedics refer low acuity patients away from hospital: a scoping review. Irish Journal of Paramedicine. 2016 Jun; 1(1)

This is an Open Access article distributed under the terms of the Creative Commons Attribution-Non-Commercial-ShareAlike 4.0 International (http://creativecommons.org/licenses/by-nc-sa/4.0/), which permits use, distribution, and reproduction in any medium, provided the original work and any attributes thereof are properly cited, are distributed under the same licence, and that the work is not used for commercial purposes.

Follow the Irish Journal of Paramedicine online at www.irishparamedicine.com, on Twitter (@irishjparamed) and on Facebook. 
REVIEW

Decision-making processes when paramedics refer low acuity patients away from hospital: a scoping review.

\author{
Kelly Sheffield MHIthSc(c), ${ }^{1,2}$, Peter O'Meara PhD ${ }^{1}$, Glenda Verrinder PhD MHIthSc ${ }^{1}$ \\ 1. La Trobe University, Victoria, Australia. \\ 2. Ambulance Victoria, Victoria, Australia.
}

Received: 03 April Revised: 09 May 2016; 06 June $2016 \quad$ Accepted: 07 June $2016 \quad$ Published: 25 June 2016

Correspondence: Kelly Sheffield, PO Box 119, Yarra Glen, Victoria, 3775, Australia. Email: sheffield.k@students.latrobe.edu.au

Abstract

\title{
Background
}

Paramedic practice faces increasing service demand with decision-making and referral pathways needing to change. Patients with low acuity clinical presentations do not necessarily require ambulance transport to an emergency department, and previous studies show alternative referral pathways can be effective, safe and efficient. With limited previous research, decision-making processes within the context of referring low acuity patients, need to be further examined.

\section{Objectives}

To examine the literature related to paramedic decision-making when referring low acuity patients to alternative care services, instead of transporting to hospital.

\section{Methods}

In this scoping review, the literature between 2005 and 2015 of service providers was examined. Key search terms were developed to search four databases and Internet search engines.

\section{Results}

Four studies were specifically related to decision-making. A further nine studies on the broader topic of paramedics referring low acuity patients to alternative medical services were included in this review.

\section{Conclusions}

Key factors including clinical experience, education, protocol use, referral processes, and holistic healthcare approaches all influence decision-making of paramedics when referring low acuity patients away from hospital. Further research into these factors is required to understand how they influence and interact with each other. Keywords: Paramedic, Emergency Medicine, Pre Hospital Care, Community Paramedicine.

\section{Introduction}

Globally, paramedics face increased service demand. $(1,2)$ Service increase has led to an examination of the contributing factors including decision-making processes within systems of paramedic practice.(2) Traditionally paramedics have conveyed patients to the emergency departments of hospitals, irrespective of how life-threatening or not the presentation was.(3) In-depth analysis of low acuity presentations and some patient sub-groups however has shown that emergency ambulance transport to hospital is not always the most appropriate option for the patient or the services.(2, 4-6) Studies have identified alternative service provision appropriate for these patients, and in some cases demonstrated better individual and service-wide outcomes.(7)

Substantial evidence demonstrates paramedics appropriately discern when patients have the ability to refuse transport and self-manage ongoing care, secondary to receiving treatment for acute conditions. $(8,9)$ Some studies however, have questioned paramedics ability to apply similar decision-making processes to patients with low acuity presentations.(10, 11) Paramedics have revealed clinical experience, knowledge of chronic conditions and social factors also influence their choice to convey patients to hospital.(8, 12, 13) Furthermore, organisational support, levels of education, continuing professional development and the availability of alternative services impact on individual decision-making.(14-16) The authors hypothesised that knowledge of patients outcome at hospital, after assessment and diagnosis, may assist decision-making for low acuity patients.(17)

\section{Methods}

A scoping review was the method of choice given this evolving area of research, the anticipated variety of methodology, limited discussion in the literature and the narrowness of the aim.(18) The aim of this scoping review was to identify existing research in decision-making by paramedics when referring low acuity patients to alternative services instead of transporting to hospital. The term decision -making relates to the influence of education, or clinical guidelines, as well as clinical experience and health service interactions. The term paramedic included the various levels and scope of practice that occur across English language journals researching ambulance and paramedic settings.(20) 
The review included nurses providing a role similar to paramedic standards in some countries, as opposed to medical practitioners whose scope of practice differs. The emerging nature of this research also influenced the timeframe of between 2005 and 2015. While articles exist prior to this time, some authors have continued to publish and their most recent work was included.(19, 20) Electronic databases and reference lists were used as well as consultation between the authors.(21) The databases deemed most appropriate for ambulance or paramedic related practice included CINAHL, Medline, ProQuest and Expanded Academic ASAP, with Google Scholar also used to find Table 1. Search Terms

1.Ambulance
2.Paramedic
3.EMT or Emergency Medical Technician
4.EMS or Emergency Medical Service
5.Paramedic practitioner
6.Referral
7.Decision making
Combine 1-7

individual citations. $(3,10,22)$ A variety of terminology is used in different countries regarding paramedic practice and so numerous key terms and combinations were used when searching databases and these are listed in Table 1.(22)

The authors developed exclusion and inclusion criteria to facilitate selection of appropriate studies, and this may have excluded some relevant research (Table 2). The review was limited to peer reviewed, published journal articles, partly due to author time constraints.(22) While many articles included some or all of the search terms, further analysis ranked the criterion for inclusion. Decision-making was the key term and many articles included analysis about the accuracy of decisions, particularly in relation to clinicians ability to predict a patients need for hospital care. $(3,10)$ The

\begin{tabular}{|l|l|l|}
\hline Table 2. Inclusion and exclusion criteria \\
\hline $\begin{array}{l}\text { Criterion } \\
\text { period }\end{array}$ & Inclusion & Exclusion \\
\hline Language & English & $\begin{array}{l}\text { Any study } \\
\text { outside of these } \\
\text { dates }\end{array}$ \\
\hline $\begin{array}{l}\text { Type of } \\
\text { article }\end{array}$ & $\begin{array}{l}\text { Original research article in } \\
\text { published peer reviewed } \\
\text { journal }\end{array}$ & $\begin{array}{l}\text { Any article that } \\
\text { was not original } \\
\text { research and/or } \\
\text { unpublished, } \\
\text { such as grey }\end{array}$ \\
\hline $\begin{array}{l}\text { Study } \\
\text { focus }\end{array}$ & $\begin{array}{l}\text { Referral and decision making } \\
\text { in non-transported ambulance } \\
\text { patients. Articles were } \\
\text { included because of their } \\
\text { focus on paramedic } \\
\text { application of decision-making, } \\
\text { or limitations of education that } \\
\text { inform decision-making issues } \\
\text { when referring patients away } \\
\text { from transport to hospital }\end{array}$ & $\begin{array}{l}\text { Articles not } \\
\text { including all } \\
\text { facets of study } \\
\text { focus }\end{array}$ \\
\hline \multicolumn{2}{|l}{}
\end{tabular}

review sought to understand the process involved in clinical decisions and so articles purely measuring accuracy and ambulance adherence to protocols were excluded.(17)

A flow chart explaining article selection is included as Figure 1. Only articles including a clear path of referral, along with decision-making, have been included.(16) Some studies suggested mixed results where paramedics appropriately left patients at home with only self-care advice, thus, these were excluded from the study.(23) Research relating to treat and discharge processes at public events were also excluded.(23) A number of the included papers were in relation to extended care programs. $(20,24)$ The aim of this review was to explore standard paramedic practice, therefore some extended care programs were included when these studies had a focus on referral and decision-making.(25) Others have been excluded due to limited decision-making analysis.(26)

Another facet of emerging paramedic practice is telephone based triage by health care professionals instead of paramedic attendance.(27) These involve referral, analysis of decision-making and sometimes using computer decision support. $(27,28)$ Only trials involving paramedics physically attending patients were included, as data suggests dispatch coding tends to over triage, and referral is likely to occur.(29) The most recent research of this nature was excluded as there was limited analysis of decision-making and referral elsewhere.(30) Some articles complicated this inclusion criterion, by having computer decision support as part of in person assessment, or related to patients left at home with only self-care advice.(28, 31) These articles however, included detailed analysis of decision-making and referral possibilities, and were included. $(28,31)$

\section{Results}

Titles and abstracts of 531 articles were reviewed and ultimately, thirteen articles were included in the review. Four articles specifically focussed on the research question, namely Coates, Halter, Snooks, and Snooks.(15, 16, 28, 32) The remaining articles were included because of their focus on paramedic decision-making, or limitations in education regarding decision-making when referring low acuity patients away from hospital.(33) Some articles discussed specific programs with additionally trained staff referring targeted presentations away from hospital.(13) Others analysed paramedics' ability to predict patients' likelihood of requiring hospital admission.(32) These articles were only included if there was discussion of this ability relating to future referral of low acuity patients away from hospital.(10) A further three systematic reviews were excluded as the articles cited in relation to decision-making were already included in the review. $(3,34)$

Various methodologies were included and Table 3 differentiates these and provides details of the study design for each article. 


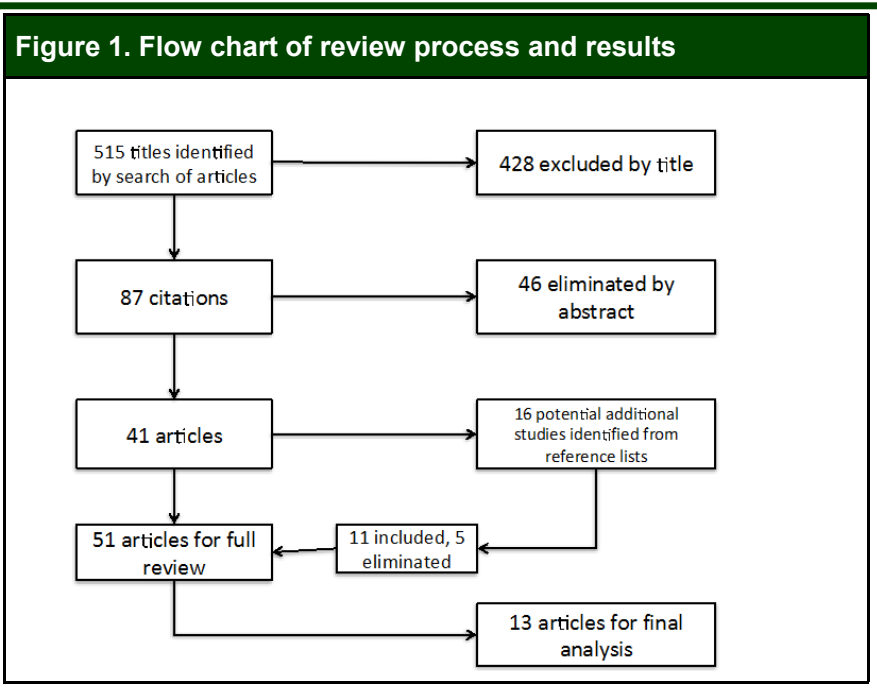

\section{Discussion}

A thematic analysis was used to draw the findings together.(39) Each article was interrogated by exploring them paragraph by paragraph to draw out similarities and differences between the articles.(39) This method of managing data and creating categories is described by Grbich as 'block and file'.(40) A process of reducing redundancy amongst the categories then occurs and a model is created that incorporates the most important themes.(40) Many studies had a mixed methods approach, allowing patient demographics to enhance and support qualitative findings. $(15,35)$ Five main themes emerged in relation to decisionmaking processes; clinical experience, protocols, education, referral processes, and holistic health care.

\section{Clinical experience}

Nearly half the articles reviewed considered clinical experience or instinct as a vital component of decisionmaking when referring low acuity patients. $(15,16,32)$ When provided with additional professional development and protocols to guide referral of low acuity patients, paramedics indicated that clinical experience heavily influenced their decisions. $(15,16,37)$ However, neither levels of experience, nor tangible ways of measuring or achieving it were discussed.(5, 32, 35) Several articles indicated that quantitative data can support paramedic and physician reliance on clinical experience levels relative to correct referral decisions. $(32,35)$

\section{Protocols}

Protocols often guide paramedic practice, and studies examining referral of low acuity patients found varying success in their use.(13, 16, 31) Adherence rates are reportedly mixed with paramedics stating that at times they used guidelines to validate decisions already made using their clinical experience. $(16,28)$ Protocols requiring consultation with other medical professionals have greater adherence and success with clinical outcomes.(25, 31) However, paramedics report that the binary nature of protocols are unhelpful when referring patients with complex clinical histories, and social circumstances.(15, 16) Reliance on protocols alone is not strongly supported and the changing nature of patients endorses more collaborative approaches. $(15,16,25)$

\section{Education}

Education was viewed as fundamental to decisionmaking.(20, 33, 36) Most articles spoke of education relating to continuing professional development by employers.(28, 35) Where the primary influence of decision-making was education, paramedics expressed increased confidence in utilising the expanded skills they had developed.(38) Cooper speculated that additional education had a direct influence on increased referral rates away from hospitals.(20) Education that focused on holistic, in-depth knowledge of complex patients and medical conditions was considered necessary as well .(13, 16, 32, 33) Education seems central to paramedic professional development, as it becomes responsive to emerging practice and essential changing needs.(33, 38) Some articles included a component of university education and as pre-employment academic education becomes more common in paramedicine, consideration must be given to when and by whom the education of particular facets of knowledge needs to occur. $(25,38)$ The varying level of academic qualifications across different paramedic locations, may also need investigation.(3, 13, 23, 38) Professional registration can facilitate education standards for research based individual and organisational responsibilities, ensuring accountability.(22) Arguably, consistency is achieved with other health care professionals, and with additional research, improved and shared referral processes.(19)

\section{Referral Processes}

Paramedics have not traditionally utilised pre-existing referral pathways when diverting low acuity patients from hospital attendance.(20,31,33) Establishing new pathways and ensuring ongoing collaboration seems to be an enduring issue that influences whether paramedics refer or not.(15) Several authors hypothesise that if paramedics received feedback on referral and patient outcomes, they would be encouraged further and be more confident in their decisionmaking.(13, 16, 28) Comans found paramedics were often identified as separate from other services and health care professionals, another factor that could influence success of referral processes.(33) Where interagency and professional collaboration occurred, paramedic satisfaction and referral rates improved.(37) In some studies, engagement with physicians or nurses facilitated higher paramedic rate of referral, as these professions more readily engage in patient referral and perhaps indicate that referral is improved by a broader understanding of health care. $(13,25)$ The complexity of influences on successful referral processes suggests perhaps an interdependence on other factors identified in this review, including collaboration with other professionals.(13, 
Table 3. Methodology \& study design of included studies

\begin{tabular}{|c|c|c|c|}
\hline \multicolumn{2}{|r|}{ Quantitative } & \multicolumn{2}{|r|}{ Qualitative } \\
\hline $\begin{array}{l}\text { Coates,(32) } \\
\text { 2012, United } \\
\text { Kingdom }\end{array}$ & $\begin{array}{l}\text { Extended care practitioners } \\
(E C P) \text { written patient records } \\
\text { reviewed by } 2 \text { doctors to } \\
\text { determine the accuracy of ECPs } \\
\text { belief these patient avoided } \\
\text { hospital attendance or admission }\end{array}$ & $\begin{array}{l}\text { Cooper,(35) } \\
\text { 2007, United } \\
\text { Kingdom }\end{array}$ & $\begin{array}{l}\text { Observation and interviews with } \\
\text { ECP's to analyse the relevant } \\
\text { factors in collaborative practice }\end{array}$ \\
\hline $\begin{array}{l}\text { Comans,(33) } \\
\text { 2013, Australia }\end{array}$ & $\begin{array}{l}\text { Referral rate of patients by } \\
\text { paramedics to falls prevention } \\
\text { service, in comparison to analysis } \\
\text { of patient records for same time } \\
\text { giving indications of potential } \\
\text { patients not referred }\end{array}$ & $\begin{array}{l}\text { Cooper,(20) } \\
\text { 2008, United } \\
\text { Kingdom }\end{array}$ & $\begin{array}{l}\text { Questionnaire form on patient } \\
\text { demographics, as well as open } \\
\text { ended questions in relation to } \\
\text { ECP's referral and collaboration } \\
\text { process }\end{array}$ \\
\hline $\begin{array}{l}\text { Gray \& Walker, } \\
\text { (36) 2008, United } \\
\text { Kingdom }\end{array}$ & $\begin{array}{l}\text { ECP impact on admission rates of } \\
\text { elderly patients with falls and } \\
\text { patients with breathing difficulties, } \\
\text { in comparison to a historical } \\
\text { group of similar patients }\end{array}$ & $\begin{array}{l}\text { Halter,(16) 2011, } \\
\text { United Kingdom }\end{array}$ & $\begin{array}{l}\text { Interviews with paramedics } \\
\text { regarding the implementation and } \\
\text { low documented use of an } \\
\text { assessment and referral tool for } \\
\text { elderly patients who have fallen }\end{array}$ \\
\hline $\begin{array}{l}\text { Haines, }(31) \\
\text { 2006, United } \\
\text { States of } \\
\text { America }\end{array}$ & $\begin{array}{l}\text { Hospital admission rates of non- } \\
\text { transported paediatric patients } \\
\text { who were referred to alternative } \\
\text { services }\end{array}$ & $\begin{array}{l}\text { Jensen,(25) } \\
\text { 2014, Canada }\end{array}$ & $\begin{array}{l}\text { Thematic analysis of focus groups } \\
\& \text { interviews with stakeholders } \\
\text { involved in extended-care } \\
\text { paramedics long-term care } \\
\text { program }\end{array}$ \\
\hline $\begin{array}{l}\text { Kue,(13) } 2009, \\
\text { United States of } \\
\text { America }\end{array}$ & $\begin{array}{l}\text { Evaluation of paramedic referral } \\
\text { of elderly patients to social } \\
\text { services program in comparison } \\
\text { to EMS physician referral of non- } \\
\text { transported patient records }\end{array}$ & $\begin{array}{l}\text { Machen,(37) } \\
\text { 2007, United } \\
\text { Kingdom }\end{array}$ & $\begin{array}{l}\text { Patient and staff perceptions of } \\
\text { nurse paramedic partnership in } \\
\text { referring patients with low priority } \\
\text { presentations, using interviews } \\
\text { and focus groups }\end{array}$ \\
\hline \multirow[t]{2}{*}{$\begin{array}{l}\text { Snooks,(28) } \\
\text { 2014, United } \\
\text { Kingdom }\end{array}$} & $\begin{array}{l}\text { RCT examining the effectiveness } \\
\text { of utilising computer clinical } \\
\text { decision support for paramedics } \\
\text { referring patients to falls service }\end{array}$ & $\begin{array}{l}\text { Reeve,(38) 2008, } \\
\text { Australia }\end{array}$ & $\begin{array}{l}\text { Examination of the experience of } \\
\text { paramedics undertaking training to } \\
\text { expand their scope of practice in } \\
\text { rural \& remote settings, utilising } \\
\text { questionnaire forms before and } \\
\text { after training }\end{array}$ \\
\hline & & $\begin{array}{l}\text { Snooks,(15) } \\
\text { 2005, United } \\
\text { Kingdom }\end{array}$ & $\begin{array}{l}\text { Analysing the views of paramedics } \\
\text { in regards to decision making prior } \\
\text { to and after the implementation of } \\
\text { treat \& refer protocols for patients } \\
\text { with non-urgent needs, using } \\
\text { focus groups }\end{array}$ \\
\hline
\end{tabular}

$14,37,38)$

\section{Holistic Healthcare}

A holistic approach including collaboration with other professionals is needed, with paramedics regularly expressing concern at their limited understanding of medical conditions and health services outside of the emergency setting.(3, 10 , $15,37)$ Jensen reports paramedics shifted the focus of their decision-making from protocol and transport considerations in long term care settings such as nursing homes.(25) Decision-making instead involved forward planning, integrating all facets of a patient's life.(25) Reinforcing this approach, national frameworks concerning chronic medical conditions now inform education and development of referral processes, rather than profession-specific interventions.(36,
38) Collaboration with other professionals consistently increases paramedic confidence and accuracy in decisionmaking as well.(13, 25, 31) With greater collaboration and an expansion of underlying healthcare knowledge, paramedics' decision-making in referring low acuity patients is enhanced.(15, 37)

The evidence of what influences decision-making became clear; articles where successful outcomes for low acuity patients and paramedic satisfaction occur, found that a balance of the various factors emerges with collaboration.(15, 37) Difficulty occurs in prioritising the factors in relation to each other, and perhaps by examining each factor individually, evidence will emerge.(24) Education and targeted professional development dominated the articles reviewed. $(20,38)$ Future research needs to investigate the 
role of education in developing decision-making skills, chronic clinical presentations and managing social welfare issues.(15) Additional consideration must be given to teaching approaches, as well as how professional registration influences responsibility for ongoing education.(22)

Many studies identified clinical experience as a factor influencing decision-making but it is argued that studies struggle to identify a tangible measure and threshold for such a dynamic component of health care professionals work.(16) By improving the contact between paramedics, medical and other health professionals, either through holistic approaches or referral pathways, factors such as clinical experience and education improve. $(25,33)$ Research may never identify a gold standard for necessary clinical experience, but examination of protocols and how they are utilised may assist.(15)

The results of this review show inconsistencies in the use of protocols. $(16,28)$ As service demand evolves, protocol use may remain in relation to acute presentations, while holistic collaboration with other health care professionals will emerge for low acuity patients.(3, 25, 37) Individual factors, chronic health variation and locational influences make it difficult to create uniform guidelines.(3, 24, 34) Further analysis of this approach must occur, along with investigation of referral processes, which also may need to be guided by individual and location factors. $(10,34)$ The evolution of paramedicine in primary care regarding low acuity patients, must be prioritised as a research focus if the profession is to truly understand the nature of current work.(3)

\section{Limitations}

This review selected studies during a particular timeframe and searched only English language papers. As a result some articles may have been missed that could have influenced the nature of this scoping review. Thematic analysis has a subjective component to it that may influence the replication of this study.

\section{Conclusion}

Paramedic practice is evolving as public demands change in the utilisation of emergency care.(3, 24) By exploring the paramedic process in referring low acuity patients away from hospital attendance, this review has sought to identify factors influencing decision-making in this area. Previous studies suggest that clinical experience, protocols, education, referral processes, and holistic healthcare approaches, all influence how paramedics navigate referral of patients. From this, further analysis of each factor is required, as well as the interaction between each of them. As paramedicine changes consideration must be given to how these factors influence wider health policy, pre-employment university education, and ongoing organisation support mechanisms for the paramedic workforce.

\section{References}

1. Lowthian JA, Cameron PA, Stoelwinder JU, Curtis A, Currell A, Cooke MW, et al. Increasing utilisation of emergency ambulances. Australian Health Review. 2011;35(1):63-9.

2. Cooper S, Grant J. New and emerging roles in out of hospital emergency care: A review of the international literature. International Emergency Nursing. 2009;17 (2):90-8.

3. Bigham BL, Kennedy SM, Drennan I, Morrison LJ. Expanding Paramedic Scope of Practice in the Community: A Systematic Review of the Literature. Prehospital Emergency Care. 2013;17(3):361-72.

4. Joyce CM, Wainer J, Archer F, Wyatt A, Pitermann L. Trends in the paramedic workforce: a profession in transition. Australian Health Review. 2009;33(4):53340.

5. Tiedemann A, Mikolaizak AS, Sherrington C, Segin K, Lord SR, Close JCT. Older fallers attended to by an ambulance but not transported to hospital: a vulnerable population at high risk of future falls. Australian and New Zealand Journal of Public Health. 2013;37(2):179-85.

6. Weaver MD, Moore CG, Patterson PD, Yealy DM. Medical Necessity in Emergency Medical Services Transports. American Journal of Medical Quality. 2012;27(3):250-5.

7. Logan PA, Coupland CAC, Gladman JRF, Sahota O, Stoner-Hobbs V, Robertson K, et al. Community falls prevention for people who call an emergency ambulance after a fall: randomised controlled trial2010 2010-05-11 09:21:02.

8. Burrell L, Noble A, Ridsdale L. Decision-making by ambulance clinicians in London when managing patients with epilepsy: a qualitative study. Emergency Medicine Journal. 2013;30(3):236-40.

9. Wampler DA, Molina DK, McManus J, Laws P, Manifold CA. No deaths associated with patient refusal of transport after naloxone-reversed opioid overdose. Prehospital Emergency Care. 2011;15 (3):320-4.

10. Brown LH, Hubble MW, Cone DC, Millin MG, Schwartz B, Patterson PD, et al. Paramedic determinations of medical necessity: A meta-analysis. Prehospital Emergency Care. 2009;13(4):516-27.

11. Silvestri S, Rothrock SG, Kennedy D, Ladde J, Bryant M, Pagane J. Can paramedics accurately identify patients who do not require emergency department care? Prehospital Emergency Care. 2002;6(4):387-90.

12. Gray JT, Wardrope J. Introduction of non-transport guidelines into an ambulance service: a retrospective review. Emergency Medicine Journal. 2007;24 (10):727-9.

13. Kue R, Ramstrom E, Weisberg S, Restuccia M. Evaluation of an emergency medical services-based 
social services referral program for elderly patients. Prehospital Emergency Care. 2009;13(3):273-9.

14. Hoyle S, Swain AH, Fake P, Larsen PD. Introduction of an extended care paramedic model in New Zealand. Emergency Medicine Australasia. 2012;24(6):652-6.

15. Snooks H, Kearsley N, Dale J, Halter M, Redhead J, Foster J. Gaps between policy, protocols and practice: a qualitative study of the views and practice of emergency ambulance staff concerning the care of patients with non-urgent needs. Quality and Safety in Health Care. 2005;14(4):251-7.

16. Halter M, Vernon S, Snooks H, Porter A, Close J, Moore F, et al. Complexity of the decision-making process of ambulance staff for assessment and referral of older people who have fallen: a qualitative study. Emergency Medicine Journal. 2011;28(1):44-50.

17. Levine SD, Colwell CB, Pons PT, Gravitz C, Haukoos JS, McVaney KE. How well do paramedics predict admission to the hospital? A prospective study. The Journal of Emergency Medicine. 2006;31(1):1-5.

18. Levac D, Colquhoun H, O'Brien KK. Scoping studies: advancing the methodology. Implementation Science : IS. 2010;5:69-.

19. Cooper S, Barrett B, Black S, Evans C, Real C, Williams $\mathrm{S}$, et al. The emerging role of the emergency care practitioner. Emergency Medicine Journal. 2004;21(5):614-8.

20. Cooper S, O'Carroll J, Jenkin A, Badger B. Emergency care practitioners (ECP): Practice and performance in the UK West country - A case study. International Emergency Nursing. 2008;16(3):180-4.

21. Arksey H, O'Malley L. Scoping studies: towards a methodological framework. International Journal of Social Research Methodology. 2005;8(1):19-32.

22. O'Meara P. Community paramedics: a scoping review of their emergence and potential impact. International Paramedic Practice. 2014;4(1):5-12.

23. Swain AH, Weaver A, Gray AJ, Bailey M, Palmer SG. Ambulance triage and treatment zones at major rugby events in Wellington, New Zealand: a sobering experience. The New Zealand Medical Journal (Online). 2013;126(1372):12-24.

24. Hill H, McMeekin P, Price C. A systematic review of the activity and impact of emergency care practitioners in the NHS. Emergency Medicine Journal. 2014;31(10):853-60.

25. Jensen JL, Travers AH, Marshall EG, Leadlay S, Carter AJE. Insights into the Implementation and Operation of a Novel Paramedic Long-term Care Program. Prehospital Emergency Care. 2014;18(1):8691.

26. Mason S, Knowles E, Colwell B, Dixon S, Wardrope $\mathrm{J}$, Gorringe R, et al. Effectiveness of paramedic practitioners in attending 999 calls from elderly people in the community: Cluster randomised controlled trial.
British Medical Journal. 2007;335(7626):919 - 22.

27. Eastwood K, Morgans A, Smith K, Stoelwinder J. Secondary triage in prehospital emergency ambulance services: a systematic review. Emergency Medicine Journal. 2015;32(6):486-92.

28. Snooks H, Carter B, Dale J, Foster T, Humphreys I, Logan PA, et al. Support and Assessment for Fall Emergency Referrals (SAFER 1): Cluster Randomised Trial of Computerised Clinical Decision Support for Paramedics. PLoS ONE. 2014;9(9):e106436.

29. Dale J, Higgins J, Williams S, Foster T, Snooks H, Crouch $\mathrm{R}$, et al. Computer assisted assessment and advice for "non-serious" 999 ambulance service callers: the potential impact on ambulance despatch. Emergency Medicine Journal. 2003;20(2):178-83.

30. Tohira H, Fatovich D, Williams TA, Bremner AP, Arendts G, Rogers IR, et al. Is it Appropriate for Patients to be Discharged at the Scene by Paramedics? Prehospital Emergency Care. 2016:1-11.

31. Haines CJ, Lutes RE, Blaser M, Christopher NC. Paramedic Initiated Non-Transport of Pediatric Patients. Prehospital Emergency Care. 2006;10(2):213 -9 .

32. Coates D, Rawstorne S, Benger J. Can emergency care practitioners differentiate between an avoided emergency department attendance and an avoided admission? Emergency Medicine Journal. 2012;29 (10):838-41.

33. Comans TA, Currin ML, Quinn J, Tippett V, Rogers A, Haines TP. Problems with a great idea: referral by prehospital emergency services to a community-based falls-prevention service. Injury Prevention. 2013;19 (2):134-8.

34. Ball L. Setting the scene for the paramedic in primary care: a review of the literature. Emergency Medicine Journal. 2005;22(12):896-900.

35. Cooper S, O'Carroll J, Jenkin A, Badger B. Collaborative practices in unscheduled emergency care: role and impact of the emergency care practitioner-qualitative and summative findings. Emergency Medicine Journal. 2007;24(9):625-9.

36. Gray JT, Walker A. Avoiding admissions from the ambulance service: a review of elderly patients with falls and patients with breathing difficulties seen by emergency care practitioners in South Yorkshire. Emergency Medicine Journal. 2008;25(3):168-71.

37. Machen I, Dickinson A, Williams J, Widiatmoko D, Kendall S. Nurses and paramedics in partnership: Perceptions of a new response to low-priority ambulance calls. Accident and Emergency Nursing. 2007;15(4):185-92.

38. Reeve C, Pashen D, Mumme H, De La Rue S, Cheffins T. Expanding the role of paramedics in northern Queensland: An evaluation of population health training. Australian Journal of Rural Health. 
2008;16(6):370-5.

39. Talbot LV, H. Turn a stack of papers into a literature review : useful tools for beginners. Focus on Health Professional Education. 2008;10(1):51-8.

40. Grbich CF. Qualitative data analysis : an introduction. London: London : SAGE; 2007.

\section{Author contributions}

KS was the principal author of the manuscript and performed the literature review. POM and GV validated the literature review and contributed to the final editing.

\section{Source of support/funding: None.}

Conflict of interest: POM is a member of the editorial board of the IJP.

Provenance and review: Not commissioned, peerreviewed.

This is an Open Access article distributed under the terms of the Creative Commons Attribution-Non-Commercial-ShareAlike 4.0 International (http:// creativecommons.org/licenses/by-nc-sa/4.0/), which permits use, distribution, and reproduction in any medium, provided the original work and any attributes thereof are properly cited, are distributed under the same licence, and that the work is not used for commercial purposes. Content copyright remains with the authors, who grant the IJP a licence to reuse and distribute. 